\title{
Dung avoidance as a possible mechanism in competition between wild and domestic ungulates: two experiments with chamois Rupicapra rupicapra
}

\author{
Regine Fankhauser • Cordula Galeffi • Werner Suter
}

Received: 22 March 2007 /Revised: 24 May 2007 / Accepted: 25 May 2007 / Published online: 19 June 2007

(C) Springer-Verlag 2007

\begin{abstract}
Wild ungulates often adjust spatial behaviour where they coexist with livestock. In European mountains, chamois Rupicapra rupicapra or $R$. pyrenaica commonly avoid alpine pastures used by domestic sheep. Mechanisms leading to competitive losing out of the wild species are not well understood, but mostly, resource competition is inferred and sometimes demonstrated. We hypothesised that chamois need to minimise the risk of intestinal parasite uptake and therefore would avoid pastures contaminated with sheep dung. We tested this in two experiments by contaminating feeding patches of wild and captive chamois with (parasitefree) sheep faeces. Wild chamois did not avoid grazing sites or plots on which sheep dung had been placed at a (low) density representing the commonly encountered situation in the Swiss Alps. Captive chamois strongly reduced browsing time on small trees given for food when the surroundings of
\end{abstract}

Communicated by W. Lutz

Present address:

R. Fankhauser

Kaden \& Partner AG,

Bahnhofstrasse 43,

8500 Frauenfeld, Switzerland

Present address:

C. Galeffi

Zoo Zürich,

Zürichbergstrasse 221,

8044 Zurich, Switzerland

Present address:

W. Suter $(\bowtie)$

Swiss Federal Research Institute WSL,

Zürcherstrasse 111,

8903 Birmensdorf, Switzerland

e-mail: werner.suter@wsl.ch the trees were sprayed with a watery faecal solution. We concluded that the odour signalled a potential high risk of parasite infection to the captive chamois, whereas the density of sheep dung on the grazing site of wild chamois was not high enough to be perceived as a risk. The need to minimise endoparasite uptake from faeces may therefore play a role in driving spatial behaviour of wild ungulates and could result in competitive imbalance between wild and domestic ungulates.

Keywords Ungulates · Parasites · Nematodes ·

Faecal avoidance $\cdot$ Domestic sheep

\section{Introduction}

Where livestock and wild ungulates share a common range, they tend to segregate at small spatial or temporal scales. This is often a one-sided process in that only the wild species adjust habitat use or feeding behaviour, while the domestic species remain indifferent to their wild counterparts (Loft et al. 1993; Fritz et al. 1996; Stewart et al. 2002; Acevedo et al. 2007). The result may be seen as an indirect displacement of wild by domestic ungulates and thus as a competitive losing out by the wild species (Voeten and Prins 1999; Stewart et al. 2002). Mechanisms underlying such processes have rarely been investigated in detail. Food limitation through intensive grazing by the domestic species was repeatedly found or inferred, and the nature of the interaction has then been explained as resource competition (Baldi et al. 2001; Mishra et al. 2004). The common situation reported in most studies is that one or several domestic species strongly outnumber the wild ungulates (e.g., Baldi et al. 2001). As often domestic cattle are involved (Loft et al. 1991, 1993; Jenks et al. 1996; Kie 1996; Mishra et al. 2004), the domestic species is usually also superior in body size. 
However, outright scramble competition involving aggressive interactions does not seem to be common, and displacement of wild species has often been treated as some sort of interference competition to which the wild species seem to be more susceptible. Beyond proximate explanations, however, there must be ultimate reasons, and it has been suggested that spatial avoidance of domestic herbivores may be linked to the need of the wild species to avoid transmission of disease or parasites (Moore 2002). Obviously, the different explanations involving resource limitation and sanitary considerations need not be mutually exclusive.

Endoparasites, in particular generalist species, can have profound effects on ruminant populations, such as reducing reproductive success, growth rate and survival (Hart 1990), even at subclinical levels where signs of disease might not be apparent (Zaffaroni et al. 1997; Gunn and Irvine 2003). Ruminants therefore have evolved behavioural strategies to reduce the impact of parasite load, among them adaptations to minimise the uptake of parasites while feeding (Hart 1990; Lozano 1991). One way to achieve this goal is by avoiding the swards around dung heaps because eggs of intestinal parasites are excreted with faeces, and after hatching, larvae spread into the surroundings (Sykes and Coop 1977; Sykes 1987; Hart 1990; Smith et al. 2006). Most studies of parasite effects refer to domestic ruminants, but consequences for wild ungulates are known to be similar (van der Wal et al. 2000; Gunn and Irvine 2003), as wild and domestic species can suffer from the same viral and bacterial infectious diseases (Nicolet and Freundt 1975; Mayer et al. 1996) and can host the same parasites (Kutzer 1988; Roberts et al. 2002). However, dung avoidance behaviour has rarely been studied in wild ungulates (van der Wal et al. 2000; Ezenwa 2004).

In European mountains, wild chamois (Rupicapra rupicapra) or isard ( $R$. pyrenaica) coexist over wide areas with domestic sheep (Ovis aries) kept on alpine pastures during summer. There are some 430,000 sheep pastured in the Swiss Alps, and they outnumber chamois by almost five to one on average, while locally the ratio may still be considerably higher. Spatial segregation between the two species at the expense of chamois was noted by several authors (Rebollo et al. 1993; R. Fankhauser et al., unpublished data), but underlying mechanisms have been little studied, although avoiding the risk of infectious disease transmission has been suggested (Ryser-DeGiorgis et al. 2002). Nematode parasite communities are known to be quite similar in chamois and domestic sheep and include Telodorsagia circumcincta, an abomasal nematode species potentially pathogenic with a high prevalence in both chamois and sheep (Balbo et al. 1978; Zaffaroni et al. 1996, 2000; Roberts et al. 2002). Feeding on pastures littered with sheep dung in high density may thus pose a serious risk to chamois of becoming infected with potentially harmful parasites. We hypothesised that chamois would exhibit similar avoidance behaviour towards sheep dung as shown by the domestic ruminants. To test this idea, we conducted two experiments. In the first experiment, we contaminated natural feeding sites of wild chamois with sheep faeces and 'dummy' dung in densities comparable to those normally found on sheep pastures and recorded behavioural responses of the chamois. In the second experiment, we used captive chamois and sprayed a watery dung solution at their feeding site to simulate stronger contamination, although we did not apply it to the food directly. We again recorded behavioural responses of chamois to different treatments.

\section{Materials and methods}

\section{Experiment 1}

The experiment was performed in a game reserve $\left(20 \mathrm{~km}^{2}\right)$ at mount Augstmatthorn $(2,137 \mathrm{~m}$ elevation) in the Bernese Alps, Switzerland $\left(46^{\circ} 44^{\prime} 32^{\prime \prime}, 7^{\circ} 55^{\prime} 43^{\prime \prime}\right)$, where hunting has been prohibited since 1909. Present chamois densities are high (e.g., 230-290 individuals were counted on 600 ha in the central part of the reserve in 1994/1995, R. Francheschina, personal communication). The reserve also holds some 50 Alpine ibex (Capra ibex), but the two species tend to be spatially segregated. There are no domestic sheep kept in the study area.

The experimental site was established in the central part of the north-facing slope of mount Augstmatthorn at $1,600 \mathrm{~m}$. The slope is evenly steep and predominantly covered by a mosaic of subalpine meadows, boulders and scree. In its lowest part, there is sparse coniferous wood growth. The site was within the home range of a group of about 30 female chamois and their kids and a few young males. Their daily routine was to spend the night on the south-facing slope of mount Augstmatthorn but to move to the north-facing slope to feed during the day. While foraging, they descended through the experimental site to the foot of the slope and, later in the day, slowly ascended through the experimental site again and returned to the south slope for the night. During rainy weather, they tended to remain on the south slope.

The experiment addressed two aspects of the hypothesis that contamination of food patches with sheep faeces affects feeding by chamois, on two spatial scales each. First, we tested whether there was an effect on the numbers of chamois present, either in the entire experimental site (larger scale) or only on the treated plots (smaller scale). Second, as dung might affect grazing behaviour rather than overall numbers present, we compared proportions of types of behaviour between the two periods, hypothesising that the proportion of grazing would decrease after contamination. Again, we compared data for the entire experimental 
site and for the different plot treatments separately, alternatively hypothesising that chamois might respond to contamination only at a small scale by avoiding just the immediate surroundings of dung.

The layout consisted of a grid of 18 adjacent plots (50× $50 \mathrm{~m}$ each) in three rows and six columns, laid out on a subalpine meadow with an average of $10-15 \mathrm{~cm}$ sward height. The corners of the plots were marked with $1-\mathrm{m}$ long posts carrying coloured tags that identified the plots individually. We applied the scan sampling method (Altmann 1974) with an observation interval of $15 \mathrm{~min}$ to record chamois numbers and their behaviours (grazing, lying, walking and standing) in each plot (=behavioural records). The 18 plots were left untreated during the first observation period (=control period, 9-27 July 2001). In the second period (=trial period, 6 August -3 September 2001), one of three treatments was randomly assigned to each plot: six plots were contaminated with sheep faeces, six plots received pine tree bark to serve as 'dummy' faeces and six plots were left untreated. The density of sheep and 'dummy' faeces were kept at one dung heap per square meter so as to mimick the normal level on alpine sheep pastures away from latrine areas (R. Fankhauser and S. Schlatter, unpublished data). On each dung plot, a total of $17 \mathrm{~kg}\left(7 \mathrm{~g} / \mathrm{m}^{2}\right)$ of fresh sheep dung was deployed. The dung was obtained from two organic farms where the sheep were practically parasite-free. For 'dummy' faeces, we used pine tree bark that was similar to sheep dung in size, colouration, texture and form but was much lighter. When fresh, it possessed a resinous smell, and we exposed it to the weather during several weeks before the experiment until it had lost its odour (at least to the human nose!). About $6 \mathrm{~kg}$ of dry weight was deployed on each 'dummy' plot to produce the same density as on the dung plots.

We calculated the sum of animals per scan and type of behaviour for each plot in both periods. To account for unequal period lengths and hence numbers of scan samples, we used proportions of behaviour types to test for differences between plots according to treatments and periods. We applied Kruskal-Wallis and chi-square tests using SPSS 11.0 for Windows (Norusis 2002).

\section{Experiment 2}

The second experiment was carried out in Goldau Zoo, an animal park at Arth Goldau, central Switzerland that specialises in displaying native species. There were five chamois kept in one enclosure (two adult females, two kids and one yearling). The experiment took place in late autumn (November/December 2001) and built upon the normal routine of how the animals were being fed. Because at this time of the year there was little ground vegetation left in the enclosure, the chamois were offered a small portion of pellets every morning and late afternoon. Additionally, with the morning feeding, they received a fresh, small silver fir tree (Abies alba), which was mounted on an old tree stump in the enclosure to be browsed by the chamois during the day.

For this experiment, we hypothesised that a sufficiently strong contamination with faeces would prompt the chamois to avoid a feeding patch and tested whether the contamination would be recognised by olfactory cues (Hutchings et al. 1998; Cooper et al. 2000). We used a watery solution of sheep faeces to produce such contamination. As a control, we first applied pure water each morning on 5 days $(15,16,19,20$, and 22 November 2001) before the faecal solution was brought out on another 5 days $(26,27,28,30$ November and 3 December 2001). Both water and solution were sprayed only to the tree stump below the small fir tree, thus treating only the surroundings and not the food itself. Due to sanitary requirements by the animal park, all sheep faeces used had been tested for parasites before application, and only parasite-free sheep dung was used. During the ten trial days, total time spent browsing on the silver fir tree was recorded for each individual chamois by continuously watching the animals. Differences between the treatments were tested using the Wilcoxon test.

\section{Results}

\section{Experiment 1}

Because of inclement weather with many rainy, foggy or cold days, chamois were present on the experimental site on only 11 days during the control (19 days, without dung) and trial periods (29 days, with dung). Total watch duration on these 11 days was $84 \mathrm{~h}$ during the control and $73 \mathrm{~h}$ during the trial period, producing 2,085 and 1,492 behavioural records, respectively (Table 1). The difference was relatively larger for behavioural records than for observation
Table 1 Types of behaviour shown by chamois during control and trial periods

Time $=$ total observation time in hours, $n=$ sum of behavioural records, $\%=$ proportion of type of behaviour in $\%$

\begin{tabular}{|c|c|c|c|c|c|c|c|c|c|c|}
\hline \multirow[t]{2}{*}{ Period } & \multirow[t]{2}{*}{ Time (h) } & \multicolumn{2}{|c|}{ Grazing } & \multicolumn{2}{|l|}{ Lying } & \multicolumn{2}{|c|}{ Walking } & \multicolumn{2}{|c|}{ Standing } & \multirow{2}{*}{$\begin{array}{l}\text { Total } \\
n\end{array}$} \\
\hline & & $n$ & $\%$ & $n$ & $\%$ & $n$ & $\%$ & $\mathrm{n}$ & $\%$ & \\
\hline Control & 84 & 545 & 26 & 1,059 & 51 & 178 & 9 & 303 & 14 & 2,085 \\
\hline Trial & 73 & 586 & 39 & 669 & 45 & 99 & 7 & 138 & 9 & 1,492 \\
\hline
\end{tabular}




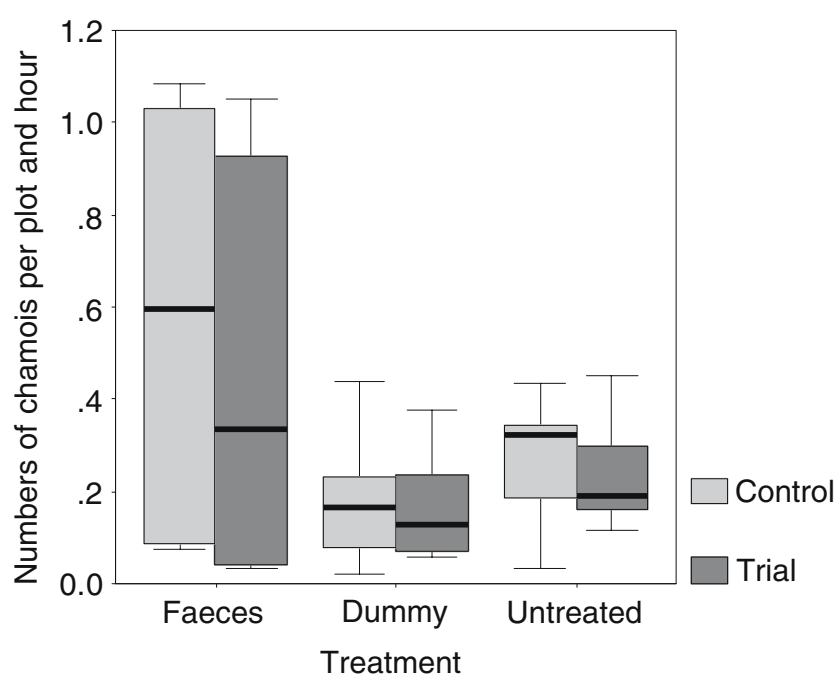

Fig. 1 Numbers of chamois recorded per hour and plot according to treatment, during the control and trial periods

hours due to the higher number of chamois present during the control period.

At the scale of the entire experimental site, there was no evidence that chamois presence differed between control and trial period. The number of animals per hour and plot ranged from 0.021 to 1.086 (mean, 0.345 ) in the control period and from 0.034 to 1.052 (mean, 0.285 ) in the trial period and did not significantly differ between the two periods (Kruskal-Wallis test, $n=18, U=144, z=-0.57, p=$ 0.569 ). There was also no sign that chamois redistributed within the experimental site after dung deployment, as plot use by treatment did not differ between periods, showing strong individual variability (Fig. 1).

Grazing intensity on the entire site also did not decrease after dung was brought in. Although the proportions of behaviour types ("grazing", "lying", "walking" and "standing"; Table 1) significantly differed between control and trial periods (chi-square test, $p<0.001$ ), changes were in fact to the opposite than expected. "Grazing" was more frequent in the trial (39\%) than in the control period $(26 \%$; chi-square test for "grazing" and "lying/walking/standing",

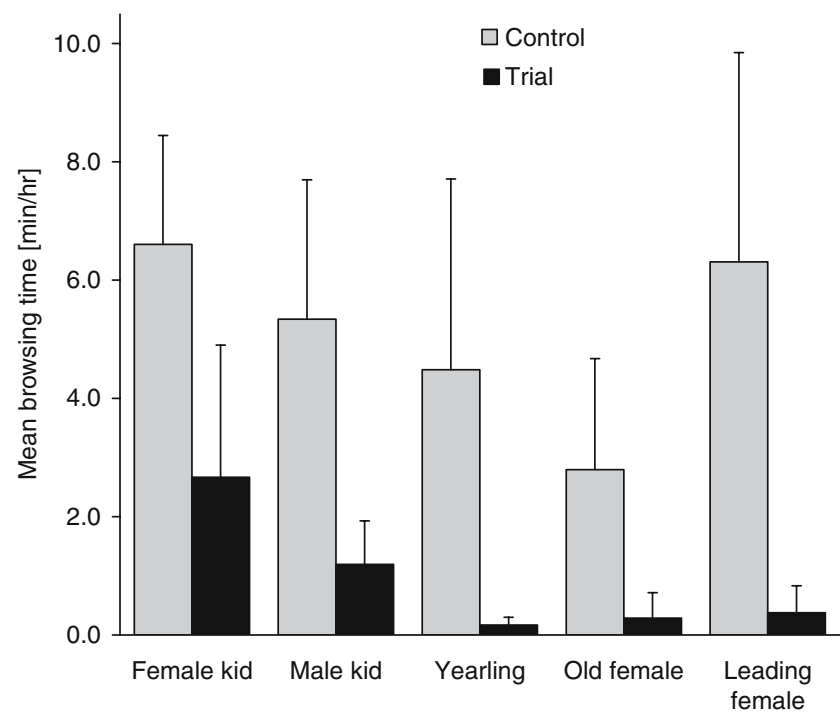

Fig. 2 Mean hourly browsing times (and standard deviations; $n=$ 5 days with $5.5 \mathrm{~h}$ of observation per period) of the captive chamois feeding on the silver fir tree when water (control period), and a watery solution of sheep faeces (trial period) was sprayed to the supporting tree stump

$p<0.001)$. There were also no differences on the plot scale according to plot treatment. Proportions of grazing were similarly higher in the trial than in the control period for dung, dummy and control treatments, whereas proportions of the other behaviour types mostly decreased to a similar extent between treatments (Table 2). This resulted in frequency distributions by treatments that were not different between periods for all four behaviour types (chi-square, $p$ ranging from 0.484 to $0.751, N=18$, Table 2).

\section{Experiment 2}

In the first period, when only water was applied to the tree stump, the five chamois together browsed on average $25.5 \mathrm{~min}$ per hour on the silver fir. In the second period, when a watery solution of sheep faeces was applied to the tree stump, the animals together spent only an average of $4.7 \mathrm{~min}$ per hour browsing on the silver fir. All five individuals

Table 2 Proportion of types of behaviour (\%) according to different treatments in control and trial periods and test statistics for each behaviour type compared between trial and control periods

\begin{tabular}{|c|c|c|c|c|c|c|c|c|c|c|c|c|}
\hline \multirow[t]{2}{*}{ Period } & \multicolumn{3}{|c|}{ Grazing (\%) } & \multicolumn{3}{|c|}{ Lying (\%) } & \multicolumn{3}{|c|}{ Walking (\%) } & \multicolumn{3}{|c|}{ Standing (\%) } \\
\hline & $\mathrm{f}$ & d & $\mathrm{u}$ & $\mathrm{f}$ & $\mathrm{d}$ & $\mathrm{u}$ & $\mathrm{f}$ & $\mathrm{d}$ & $\mathrm{u}$ & $\mathrm{f}$ & d & $\mathrm{u}$ \\
\hline Control & 17 & 45 & 33 & 63 & 29 & 40 & 5 & 13 & 13 & 15 & 14 & 15 \\
\hline Trial & 29 & 56 & 48 & 56 & 32 & 33 & 5 & 8 & 9 & 11 & 4 & 11 \\
\hline $\mathrm{Chi}^{2}$ & & 1.39 & & & 0.71 & & & 0.57 & & & 1.45 & \\
\hline$p$ & & 0.50 & & & 0.70 & & & 0.75 & & & 0.48 & \\
\hline
\end{tabular}

Chi-square test on the original frequencies, $n=18$ plots, $d f=2$

$f$ Faeces, $d$ dummy, $u$ untreated 
reduced their browsing time significantly during the contamination period (Fig. 2; Wilcoxon test, $N=25, Z=-4.345$, $p<0.001)$.

\section{Discussion}

Anti-parasitic behaviour in animals includes a variety of adaptations and strategies, the primary one being simply to avoid food items that are a source of parasites (Hart 1990; Lozano 1991). Grazing ungulates face the risk of ingesting larval endoparasites that develop in faeces deposited by the ungulates themselves, and they should therefore ignore swards next to fresh droppings. Such avoidance behaviour is known to occur in domestic ruminants (Pain et al. 1974; Hart 1990; Bao et al. 1998; Cooper et al. 2000; Gunn and Irvine 2003) and has recently also been found in wild ungulates (van der Wal et al. 2000; Ezenwa 2004). However, mechanisms of faecal-oral parasite transmission in free-ranging ruminants are not well understood, and important questions remain largely unanswered, e.g. how the infection risk varies with spatial and temporal patterns of dung accumulation and decomposition, or how animals are able to assess the risk and integrate it in foraging decision trade-offs (Hutchings et al. 2006).

We used parasite-free sheep faeces for our experiments because our a priori hypothesis that dung avoidance was the mechanism to minimise the risk of parasite uptake did not assume that the ungulates were able to detect parasites directly and thus distinguish between parasite-infected and parasite-free faeces. Cooper et al. (2000) found that sheep did not react to feeding patches experimentally infested with nematode larvae only, and although the sheep discriminated against patches contaminated with faeces, they did not discern between faeces from infected and uninfected animals. Thus, the presence of faeces rather than the parasites themselves seems to be the primary cue for risk assessment (Hutchings et al. 2003), but odour may mediate the strength of the behavioural reaction (Dohi et al. 1991; Aoyama et al. 1994). Hutchings et al. (1998) found that fresh faeces were more odoriferous and provoked stronger rejections of contaminated swards by sheep than older faeces.

In our experiment with wild chamois, we deployed fresh sheep dung at a similar density $\left(1\right.$ heap $\left./ \mathrm{m}^{2}\right)$ as that produced by sheep on alpine pastures away from latrine areas. We therefore simulated the situation commonly encountered by chamois over much of the Alps. However, we did not detect any avoidance behaviour by the chamois on the two spatial levels addressed. While several studies found that ungulates reacted to dung contamination by avoiding entire feeding patches (Pain et al. 1974; van der Wal et al. 2000), or at least by spending less time feeding there
(Cooper et al. 2000), in other studies, no avoidance was observed (White and Hall 1998; Daniels et al. 2001). Ungulates often seem to react to contaminated swards at rather small spatial scales by decreasing bite depth, bite mass and bite frequency in swards immediately around dung heaps (Hutchings et al. 1998, 2002). In addition, these behavioural modifications occur only above certain thresholds of faecal concentration: Hutchings et al. (1998) found significant levels of sward rejection by sheep only from faecal densities of $198 \mathrm{~g} / \mathrm{m}^{2}$ upwards, much higher than the $7 \mathrm{~g} / \mathrm{m}^{2}$, which we used to simulate realistic contamination. Possibly, the infection risk is not high enough at such density to trigger avoidance behaviour in chamois. However, we cannot exclude that the chamois modified bite actions in swards immediately around dung heaps and thus reacted to the presence of sheep dung at a micro-scale not amenable to observation in our field situation.

In our second experiment with captive chamois, we found a strong avoidance reaction in all five individuals after a watery solution of sheep faeces was sprayed on the tree stump on which the fir tree was mounted, despite the faeces originating from parasite-free sheep. As the solution was not applied on the forage plant itself and also offered no visual signal, it is most likely that the smell was the responsive cue for the chamois to reduce foraging. These results link to several studies that reported strong aversion towards swards treated with manure or slurry (Pain et al. 1974; Suárez and Orihuela 2002) and that odour was the cue used by the animals (Dohi et al. 1991; Aoyama et al. 1994). Odour may convey two slightly different types of information: Firstly, odour intensity can be seen as a measure of faecal density, and secondly, strong odour in faeces could indicate reduced health and thus higher parasite load (Bekele 2002). In both cases, however, strong odour would be a sign of high infection risk.

Inter-specific dung avoidance has rarely been addressed (Benham and Broom 1991; Aoyama et al. 1994; Daniels et al. 2001) and hardly ever in a wider context of interspecific relationships (Gunn and Irvine 2003). Our results suggest that competitive imbalance between wild and domestic ungulates, particularly avoidance of feeding patches or habitats by the wild species, should not only be interpreted in terms of resource (or interference) competition but should also be considered under the aspect of different risk perception and susceptibility to infection with parasites and other pathogens excreted in faeces.

Acknowledgements We thank M. Zuber and B. Dauwalder (Game Service, Canton of Berne) for making the field station in the Mt. Augstmatthorn Game Reserve available for us, and E. Andermatt and M. Wehrle (Goldau Zoo) for the opportunity to perform the experiment in Goldau Zoo. For assistance in the field, we thank T. Bleuler, Ch. Bürki, D. Cisana, B. Galeffi, G.F. Galeffi, S. Galeffi, V. Lamperière, F. Oechslin, N. Rohner, S. Stadelmann, P. Waeber, G. 
Wettstein, and J. Zingg. U. Pfister and H.P. Wüthrich kindly provided the dung from parasite-free sheep. S. Krackow and B. König (Zoological Institute, University of Zurich) helped with the experimental design and analysis, and P.J. Edwards (Geobotanical Institute, Swiss Federal Institute of Technology, Zürich), H. Richner (Zoological Institute, University of Bern) and J. Senn (WSL) had a critical look at an earlier version of the manuscript. This study was part of a project founded by the Swiss Agency for the Environment, Forests and Landscape.

\section{References}

Acevedo P, Cassinello J, Gortazar C (2007) The Iberian ibex is under an expansion trend but displaced to suboptimal habitats by the presence of extensive goat livestock in central Spain. Biodivers Conserv (in press) DOI 10.1007/s10531-006-9032-y

Altmann J (1974) Observational study of behaviour: Sampling methods. Behaviour 49:227-267

Aoyama M, Dohi H, Shioya S, Takeuchi Y, Mori Y, Okubo T (1994) Feeding-deterrent substance in cattle faeces: its effects on ingestive behavior in goats. Appl Anim Behav Sci 40:253-262

Balbo T, Costantini R, Lanfranchi P, Gallo MG (1978) Raffronto comparativo della diffusione dei nematodi gastro-intestinali nei ruminanti domestici (Ovis aries e Capra hircus) e nei ruminanti selvatici (Capra ibex e Rupicapra rupicapra) delle Alpi occidentali. Parassitologia 20:131-137

Baldi R, Albon SD, Elston DA (2001) Guanacos and sheep: evidence for continuing competition in arid Patagonia. Oecologia 129:561-570

Bao J, Giller PS, Stakelum G (1998) Selective grazing by dairy cows in the presence of dung and the defoliation of tall grass dung patches. Anim Sci 66:65-73

Bekele T (2002) Epidemiological studies on gastrointestinal helminths of dromedary (Camelus dromedarius) in semi-arid lands of eastern Ethiopia. Vet Parasitol 105:139-152

Benham PFJ, Broom DM (1991) Responses of dairy cows to badger urine and faeces on pasture with reference to bovine tuberculosis transmission. Br Vet J 147:517-532

Cooper J, Gordon IJ, Pike AW (2000) Strategies for the avoidance of faeces by grazing sheep. Appl Anim Behav Sci 69:15-33

Daniels MJ, Ball N, Hutchings MR, Greig A (2001) The grazing response of cattle to pasture contaminated with rabbit faeces and the implications for the transmission of paratuberculosis. Vet $\mathrm{J}$ 161:306-313

Dohi H, Yamada A, Entsu S (1991) Cattle feeding deterrents emitted from cattle feces. J Chem Ecol 17:1197-1203

Ezenwa VO (2004) Selective defecation and selective foraging: Antiparasite behavior in wild ungulates. Ethology 110:851-862

Fritz H, de Garine-Wichatitsky M, Letessier G (1996) Habitat use by sympatric wild and domestic herbivores in an African savanna woodland: the influence of cattle spatial behaviour. J Appl Ecol 33:589-598

Gunn A, Irvine RJ (2003) Subclinical parasitism and ruminant foraging stategies - a review. Wildl Soc Bull 31:117-126

Hart BL (1990) Behavioural adaptations to pathogens and parasites: Five strategies. Neurosci Biobehav Rev 14:273-294

Hutchings MR, Kyriazakis I, Anderson DH, Gordon IJ, Coop RL (1998) Behavioural strategies used by parasitized and nonparasitized sheep to avoid ingestion of gastro-intestinal nematodes associated with faeces. Anim Sci 67:97-106

Hutchings MR, Gordon IJ, Kyriazakis I, Robertson E, Jackson F (2002) Grazing in heterogeneous environments: infra- and supraparasite distributions determine herbivore grazing decisions. Oecologia 132:453-460
Hutchings MR, Athanasiadou S, Kyriazakis I, Gordon IJ (2003) Can animals use foraging behaviour to combat parasites? Proc Nutr Soc 62:361-370

Hutchings MR, Judge J, Gordon IJ, Athanasiadou S, Kyriazakis I (2006) Use of trade-off theory to advance understanding of herbivore-parasite interactions. Mammal Rev 36:1-16

Jenks JA, Leslie DM, Lochmiller RL, Melchiors MA, McCollum FT (1996) Competition in sympatric white tailed deer and cattle populations in southern pine forests of Oklahoma and Arkansas, USA. Acta Theriol 41:287-306

Kie JG (1996) The effect of cattle grazing on optimal foraging in mule deer (Odocoileus hemionus). For Ecol Manag 88:131-138

Kutzer E (1988) Bedeutung parasitärer Wechselinfektionen bei Hausund Wildwiederkäuern. Mh Vet Med 43:577-580

Loft ER, Menke JW, Kie JG (1991) Habitat shifts by mule deer-the influence of cattle grazing. J Wildl Manage 55:16-26

Loft ER, Kie JG, Menke JW (1993) Grazing in the Sierra Nevadahome range and space use patterns of mule deer as influenced by cattle. Calif Fish Game 79:145-166

Lozano GA (1991) Optimal foraging theory: a possible role for parasites. Oikos 60:391-395

Mayer D, Nicolet J, Giacometti M, Schmitt M, Wahli T, Meier W (1996) Isolation of Mycoplasma conjunctivae from conjunctival swabs of Alpine ibex (Capra ibex ibex) affected with infectious keratoconjunctivits. J Vet Med 43:155-161

Mishra C, van Wieren SE, Ketner P, Heitkönig IMA, Prins HHT (2004) Competition between domestic livestock and wild bharal Pseudois nayaur in the Indian Trans-Himalaya. J Appl Ecol 41:344-354

Moore J (2002) Parasites and the behavior of animals. Oxford University Press, New York

Nicolet J, Freundt EA (1975) Isolation of Mycoplasma conjunctivae from chamois and sheep affected with keratoconjunctivitis. J Vet Med 22:302-307

Norusis MJ (2002) SPSS 11.0 guide to data analysis. Prentice Hall, Englewood Cliffs, NJ

Pain BF, Leaver JD, Broom DM (1974) Effects of cow slurry on herbage production intake by cattle and grazing behaviour. $\mathrm{J} \mathrm{Br}$ Grassl Soc 29:85-91

Rebollo S, Robles L, Gomez-Sal A (1993) The influence of livestock management on land use competition between domestic and wild ungulates: sheep and chamois Rupicapra pyrenaica parva Cabrera in the Cantabrian range. Pirineos 141-142:47-62

Roberts MG, Dobson AP, Arneberg P, de Leo GA, Krecek RC, Manfredi MT, Lanfranchi P, Zaffaroni E (2002) Parasite community ecology and biodiversity. In: Hudson PJ, Rizzoli A, Grenfell BT, Heesterbeek H, Dobson AP (eds) The ecology of wildlife diseases. Oxford University Press, Oxford, pp 63-82

Ryser-DeGiorgis MP, Ingold P, Tenhu H, Tébar Less AM, Ryser A, Giacometti M (2002) Encounters between Alpine ibex, Alpine chamois and domestic sheep in the Swiss Alps. Hystrix (n.s.) 13:1-11

Smith LA, White PCL, Hutchings MR (2006) Effect of the nutritional environment and reproductive investment on herbivore-parasite interactions in grazing environments. Behav Ecol 17:591-596

Stewart KM, Bowyer RT, Kie JG, Cimon NJ, Johnson BK (2002) Temporospatial distributions of elk, mule deer, and cattle: resource partitioning and competitive displacement. J Mammal $83: 224-244$

Suárez E, Orihuela A (2002) The effect of exposure to feces from four farm species on the avoidance behaviour and feed consumption of sheep. Livest Prod Sci 77:119-125

Sykes AR (1987) Endoparasites and herbivore nutrition. In: Hacker JB (ed) Nutrition of herbivores. Academic, Harickvale, pp 211232 
Sykes AR, Coop RL (1977) Chronic parasitism and animal efficiency. ARC Res Rev 3:41-46

van der Wal R, Irvine J, Stien A, Shepherd N, Albon SD (2000) Faecal avoidance and the risk of infection by nematodes in a natural population of reindeer. Oecologia 124:19-25

Voeten MM, Prins HHT (1999) Resource partitioning between sympatric wild and domestic herbivores in the Tarangire region of Tanzania. Oecologia 120:287-294

White KA, Hall SJ (1998) Behaviour of lambs (Ovis aries) in relation to spatial patterns of defecation on a pasture. J Zool Lond 245:111-117
Zaffaroni E, Fraquelli C, Manfredi MT, Siboni A, Lanfranchi P, Sartori E, Partel P (1996) Abomasal helminth communities in eastern Alpine sympatric roe deer (Capreolus capreolus) and chamois (Rupicapra rupicapra) populations. Suppl Ric Biol Selvag 24:53-68

Zaffaroni E, Citterio C, Sala M, Lauzi S (1997) Impact of abomasal nematodes on roe deer and chamois body condition in an alpine environment. Parassitologia 39:313-317

Zaffaroni E, Manfredi MT, Citterio C, Sala M, Piccolo G, Lanfranchi $\mathrm{P}$ (2000) Host specificity of abomasal nematodes in free ranging alpine ruminants. Vet Parasitol 90:221-230 